\title{
Produção da mamoneira cultivada com águas salinas e doses de nitrogênio ${ }^{1}$
}

\author{
Production in the castor bean cultivated with saline water and dosages of nitrogen
}

\author{
Geovani Soares de Lima² ${ }^{2 *}$ Reginaldo Gomes Nobre ${ }^{3}$, Hans Raj Gheyi ${ }^{4}$, Lauriane Almeida dos Anjos Soares $^{2}$ e \\ Alexsandro Oliveira Silva ${ }^{5}$
}

\begin{abstract}
RESUMO - Objetivou-se com esta pesquisa avaliar a produção da mamoneira cv. BRS Energia, submetida à irrigação com água de diferentes salinidades e doses de adubação nitrogenada em experimento conduzido em lisímetros sob condições de campo na área experimental da UFCG, Pombal, PB. Usou-se a aleatorização em blocos, em esquema fatorial 5 x 4, com três repetições, testando-se a combinação de cinco níveis de condutividade elétrica da água de irrigação - CEa $(0,3 ; 1,2$; 2,1; 3,0 e 3,9 dS m${ }^{-1}$ ) e quatro doses de nitrogênio (70; 100; 130 e $160 \mathrm{mg} \mathrm{N} \mathrm{kg}^{-1}$ de solo). O incremento salino das águas de irrigação promoveu redução no número de frutos e de sementes e, na massa de sementes do racemo primário e secundário. A irrigação com água de até $3,9 \mathrm{dS} \mathrm{m}^{-1}$ prolongou a emissão do racemo primário e secundário da mamoneira, e quando submetida à irrigação com CEa de até $3,3 \mathrm{dS} \mathrm{m}^{-1}$ teve o teor de óleo nas sementes do racemo primário superior a $48 \%$. A aplicação de doses crescentes de nitrogênio aumentou o número de frutos no racemo primário e o tempo para emissão do racemo secundário. A interação entre a salinidade de água de irrigação e dose de nitrogênio afetou significativamente o comprimento efetivo do racemo primário e secundário e o teor de óleo nas sementes da produção subsequente.
\end{abstract}

Palavras-chave: Ricinus communis L. Plantas-efeito do nitrogênio. Plantas-efeito do sal.

\begin{abstract}
The aim of this research was to evaluate production of the castor bean cv. BRS Energia, when subjected to irrigation with water at different levels of salinity and to fertilization with different levels of nitrogen, in an experiment carried out using lysimeters under field conditions at the experimental area of the Federal University of Campina Grande (UFCG), in Pombal, in the state of Paraíba, Brazil. A design of randomised blocks was used in a 5 x 4 factorial, with three replications, to test the combination of five levels of electrical conductivity of the irrigation water - CEa $(0.3,1.2$, 2.1, 3.0 and $3.9 \mathrm{dS} \mathrm{m}^{-1}$ ) and four levels of nitrogen (70, 100, 130 and $160 \mathrm{mg} \mathrm{N} \mathrm{kg}^{-1}$ soil). An increase in the salinity of the irrigation water caused a reduction in the number of fruits and seeds, and in the weight of seeds on the primary and secondary raceme. Irrigation with water of up to $3.9 \mathrm{dS} \mathrm{m}^{-1}$ prolonged the issue of primary and secondary racemes in the castor bean, and when subjected to irrigation with a CEa of $3.3 \mathrm{dS} \mathrm{m}^{-1}$, the oil content of the seeds on the primary raceme was over $48 \%$. The application of increasing levels of nitrogen increased the number of fruits on the primary raceme and the time needed for emission of the secondary raceme. The interaction between the level of salinity of the irrigation water and the level of nitrogen significantly affected the effective length of the primary and secondary raceme, and the oil content in the seeds of subsequent yields.
\end{abstract}

Key words: Ricinus communis L. Plants-effect of nitrogen. Plants- effect of salt.

\footnotetext{
*Autor para correspondência

Recebido para publicação em 28/12/2012; aprovado em 21/08/2014

Parte da Dissertação de Mestrado do primeiro autor apresentada ao Programa de Pós-Graduação em Engenharia Agrícola da Universidade Federal de Campina Grande, Campus de Campina Grande-PB

${ }^{2}$ Programa de Pós-Graduação em Engenharia Agrícola, Unidade Acadêmica de Engenharia Agrícola, Universidade Federal de Campina Grande, Campina Grande-PB, Brasil, geovanisoareslima@gmal.com; laurispo.agronomia@gmail.com

${ }^{3}$ Unidade Acadêmica de Ciências Agrárias, Universidade Federal de Campina Grande, Pombal-PB, Brasil, rgomesnobre@pq.cnpq.br

${ }^{4}$ Núcleo de Engenharia de Água e Solo, Universidade Federal do Recôncavo da Bahia, Cruz das Almas-BA, Brasil, hans@pq.cnpq.br

${ }^{5}$ Unidade Acadêmica de Ciências Agrárias, Universidade Federal de Campina Grande, Pombal-PB, Brasil, alex-sandro.vip@ hotmail.com
} 


\section{INTRODUÇÃO}

Com a crise mundial em decorrência da demanda energética e a busca pela sustentabilidade ambiental, com base na substituição progressiva dos combustíveis minerais derivados do petróleo por fontes alternativas e limpas de energia, criou-se uma perspectiva real para a expansão do cultivo da mamoneira (Ricinus communis L.) em escala comercial, devido à possibilidade de uso do óleo contido em suas sementes como biodiesel (LIRA; BARRETO, 2009).

As perspectivas favoráveis na implantação racional dessa cultura para a produção de biodiesel decorrem do fato do óleo contido em suas sementes possuir características importantes como, maior densidade, solubilidade em álcool, além de ser usado na química fina em mais de 700 produtos possibilitando diversificada utilização industrial (MARINHO et al., 2010).

A região semiárida do Brasil é caracterizada por apresentar, chuvas mal distribuídas, ocorrendo déficit hídrico na maior parte dos meses do ano, desta forma, a prática da irrigação consiste na melhor alternativa de assegurar a produção agrícola. Entretanto, nesta região as águas usadas na irrigação apresentam teores relativamente elevados de sais (LIMA et al., 2008). O uso destas águas está condicionado à tolerância das culturas à salinidade e às práticas de manejo da irrigação e adubação, que devem evitar impactos ambientais e consequentes prejuízos às culturas.

Os efeitos dos sais dissolvidos na água ou no solo, na maioria dos casos, refletem-se na inibição da germinação e desuniformidade do crescimento, declínio na capacidade produtiva e na qualidade dos produtos obtidos das plantas cultivadas (ARRUDA et al., 2002) devido a redução do potencial hídrico e ao efeito iônico do acúmulo de íons principalmente, o $\mathrm{Cl}$ e o $\mathrm{Na}$ nos tecidos vegetais, uma vez que as taxas de elongação e de divisão celular dependem diretamente do processo de extensibilidade da parede celular (MUNNS; TESTER, 2008).

O balanço osmótico é essencial para o desenvolvimento dos vegetais em meio salino e qualquer falha neste balanço provoca injúrias semelhantes às da seca, como a perda de turgescência e a redução no crescimento e produção (ASHRAF; HARRIS, 2004). Segundo Fageria (1989) o mais importante mecanismo para regular o estresse osmótico, talvez seja a absorção seletiva de íons, pois plantas tolerantes possuem a capacidade de retirar nutrientes essenciais da solução salina, onde a concentração de íons não essenciais (tóxicos) é maior.

A nutrição mineral é um importante fator ambiental, sendo o nitrogênio o macronutriente exigido em maior quantidade pelas culturas agrícolas (MILLER; CRAMER, 2004) devido às funções do
$\mathrm{N}$ no metabolismo das plantas, participando como constituinte da molécula de clorofila, ácidos nucléicos, aminoácidos e proteínas. Flores et al. (2002) citam que entre os diversos efeitos da salinidade sobre as plantas, existem evidências de competição na absorção entre nitrato e cloreto, de modo que um aumento na concentração de nitrato na zona radicular pode inibir uma maior absorção de cloreto pela planta.

Neste sentido, objetivou-se com esta pesquisa, avaliar os efeitos da irrigação com água de diferentes salinidades e doses de adubação nitrogenada, sobre a produção da mamoneira cv. BRS Energia.

\section{MATERIAL E MÉTODOS}

A pesquisa foi realizada no período de setembro de 2011 a janeiro de 2012 em lisímetros de drenagem sob condições de campo em área experimental do Centro de Ciências e Tecnologia Agroalimentar (CCTA), da Universidade Federal de Campina Grande (UFCG), Pombal, PB, situada a 6 $48^{\prime} 16^{\prime \prime}$ S, 37ํ9' $15^{\prime \prime} \mathrm{W}$ e altitude média de $144 \mathrm{~m}$.

$\mathrm{O}$ delineamento experimental utilizado foi $\mathrm{o}$ de blocos ao acaso, em esquema fatorial $5 \times 4$, com três repetições, sendo as unidades experimentais arranjadas em fileiras simples espaçadas de $0,9 \mathrm{~m}$ entre fileiras e $0,7 \mathrm{~m}$ entre plantas dentro da fileira, e cujos tratamentos consistiram da combinação de cinco níveis de condutividade elétrica da água de irrigação - CEa $(0,3$; 1,$2 ; 2,1 ; 3,0$ e $3,9 \mathrm{dS} \mathrm{m}^{-1}$ ) associados a quatro doses de adubação nitrogenada (70; 100; 130 e $160 \mathrm{mg} \mathrm{N} \mathrm{kg}^{-1}$ de solo em base de dose recomendada (100 $\mathrm{mg} \mathrm{N} \mathrm{kg}^{-1}$ ) para ensaios em vasos por Novais, Neves e Barros (1991).

Os diferentes níveis de salinidade da água foram obtidos a partir da dissolução do cloreto de sódio em água proveniente do sistema de abastecimento local (CAGEPA), cuja quantidade (C) foi determinada com base na Equação 1, de Rhoades, Kandiah e Mashali (2000).

$C\left(m g L^{-1}\right)=640 \times C E a$

onde a $C E a$ representa o valor desejado da condutividade elétrica da água, em dS m${ }^{-1}$.

As respectivas águas eram acondicionadas em tonéis plásticos de $200 \mathrm{~L}$ de capacidade.

Como material vegetal, utilizou-se a cultivar de mamoneira BRS Energia, por se tratar de um material genético vigoroso, de fácil propagação, com característica de precocidade (ciclo de 130 dias), porte baixo (média de $106 \mathrm{~cm}$ ), frutos semi-indeiscentes, teor 
de óleo nas sementes em média de $48 \%$ e produtividade média de $1.800 \mathrm{~kg} \mathrm{ha}^{-1}$ (SILVA et al., 2009).

Foram utilizados na pesquisa, lisímetros de drenagem com $100 \mathrm{~L}$ de capacidade, preenchidos com $2 \mathrm{~kg}$ de brita ( ${ }^{\circ}$ zero) a qual cobria a base do vaso, seguida de $107,5 \mathrm{~kg}$ de material de solo (Neossolo Regolítico eutrófico típico de textura areia franca) não salino e não sódico, coletado à profundidade de $0-30 \mathrm{~cm}$, devidamente destorroado e proveniente do município de Pombal, PB, cujas características físicas e químicas (Tabela 1), foram obtidas conforme metodologias descritas por Claessen (1997). Os vasos possuíam dois furos na base para permitir a drenagem e abaixo dos mesmos existia garrafas plástica para acompanhamento do volume de água drenado e estimativa do consumo de água pela planta.

Realizou-se a adubação de fundação aplicando-se por lisímetro $162,5 \mathrm{~g}$ de superfosfato simples, $12 \mathrm{~g}$ de sulfato de potássio e $2,5 \mathrm{~kg}$ de vermicomposto $\left(6,3 \mathrm{~g} \mathrm{de}^{\mathrm{N} ~ \mathrm{~kg}^{-1}}\right.$;

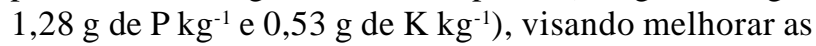
propriedades físicas, químicas e biológicas do solo, e de forma a aumentar a capacidade de retenção e infiltração da água. O material do solo após acondicionado nos lisímetros foi colocado em capacidade de campo, através do método de saturação por capilaridade, seguida por drenagem livre, usando as distintas águas conforme tratamentos.

Foram semeadas dez sementes por lisímetro a $2 \mathrm{~cm}$ de profundidade e distribuídas de forma equidistante. A emergência das plântulas teve inicio no sexto dia após o semeio (DAS) e continuou até o décimo terceiro dia. Aos 22 DAS realizou-se o primeiro desbaste, deixando-se apenas três plantas por vaso, as de melhor vigor. Aos 30 e 40 DAS foram realizados novos desbastes, onde se eliminou em cada recipiente, uma planta.

O fator adubação nitrogenada foi parcelado, sendo 1/3 aplicados em fundação e os $2 / 3$ restantes, em quatro aplicações via fertirrigação, em intervalos de dez dias a partir dos 25 DAS, sendo aplicados por recipiente no tratamento $\mathrm{N} 2$ (100 $\mathrm{mg} \mathrm{N} \mathrm{kg}^{-1}$ de solo ) 33,34 g de fosfato monoamônio (MAP) mais 8,88 $\mathrm{g}$ de uréia. A quantidade de adubo aplicada nos demais tratamentos era calculada conforme N2. Realizou-se ainda, após o início da emissão das flores, duas adubações foliares aos 29 e 37 DAS, usando Albatroz $\left(\mathrm{N}-10 \%, \mathrm{P}_{2} \mathrm{O}_{5}-52 \%, \mathrm{~K}_{2} \mathrm{O}\right.$ - $10 \%, \mathrm{Ca}-0,1 \%, \mathrm{Zn}-0,02 \%, \mathrm{~B}-0,02 \%, \mathrm{Fe}-0,15 \%, \mathrm{Mn}$ - 0,1\%, Cu - 0,02\% e M.O - 0,005\%) na proporção de $1 \mathrm{~g}$ do adubo para $1 \mathrm{~L}$ de água e aplicando-se $5 \mathrm{~L}$, distribuídos nas plantas, com auxilio de um pulverizador costal.

Após o plantio, irrigou-se diariamente às 17 horas, aplicando-se em cada lisímetro a água conforme tratamento e sendo a quantidade aplicada determinada conforme a necessidade hídrica das plantas obtida pelo balanço hídrico - volume aplicado menos o drenado -, acrescido de fração de lixiviação média de 0,10 , conforme trabalhos desenvolvidos anteriormente (NOBRE et al., 2012; NOBRE et al., 2013).

Os tratos culturais consistiram em capinas manuais feitas semanalmente, escarificação superficial do solo antes de cada irrigação e tutoramento das plantas após atingirem o estádio de floração, com o objetivo de evitar o tombamento das plantas.

Por ocasião da colheita avaliaram-se os efeitos dos tratamentos sobre a cultura a partir dos parâmetros: número de dias para emissão do racemo primário (NDRP) e secundário (NDRS); o comprimento efetivo do racemo primário (CERP) e secundário (CERS); o número de frutos no racemo primário (NFrutRP) e secundário (NFrutRS); o número de sementes no racemo primário (NSRP) e secundário (NSRS); a massa de sementes no racemo primário (MSRP) e secundário (MSRS); o teor de óleo nas sementes do racemo primário (TOrp) e na produção subsequente(TOps). A produção subsequente foi considerada como o somatório dos racemos produzidos por planta a partir da segunda ordem até o final do ciclo da cultura.

Estimou-se o NDRP e o NDRS por meio do acompanhamento diário do surgimento da inflorescência. O CERP e o CERS foram mensurados conforme a distância entre a inserção dos frutos na base e o ápice do racemo. A colheita dos racemos foi realizada manualmente e teve início aos 67 DAS e continuou até aos 120 DAS, quando aproximadamente $90 \%$ dos frutos

Tabela 1- Características físicas e químicas do solo utilizado no experimento

\begin{tabular}{|c|c|c|c|c|c|c|c|c|c|c|c|}
\hline \multirow{2}{*}{ Densidade } & \multirow{2}{*}{$\begin{array}{c}\text { Porosidade } \\
\text { Total }\end{array}$} & \multirow{2}{*}{ Areia } & \multirow{2}{*}{ Silte } & \multirow{2}{*}{ Argila } & \multirow{2}{*}{ M.O. } & \multicolumn{4}{|c|}{ Complexo Sortivo } & \multirow{2}{*}{$\mathrm{pH}_{\mathrm{ps}}$} & \multirow{2}{*}{$\mathrm{CE}_{\mathrm{es}}$} \\
\hline & & & & & & $\mathrm{Ca}^{+2}$ & $\mathrm{Mg}^{+2}$ & $\mathrm{Na}^{+}$ & $\mathrm{K}^{+}$ & & \\
\hline $\mathrm{g} \mathrm{cm}^{-3}$ & $\%$ & - ------ & $---\mathrm{g} 1$ & r-1-.-. & ------ & - ------ & $-\mathrm{cmo}$ & $\mathrm{g}^{-1}--\cdot$ & ----- & - & $\mathrm{dS} \mathrm{m}^{-1}$ \\
\hline 1,34 & 48,26 & 490 & 170 & 340 & 108 & 3,95 & 3,70 & 0,37 & 0,43 & 5,01 & 0,09 \\
\hline
\end{tabular}

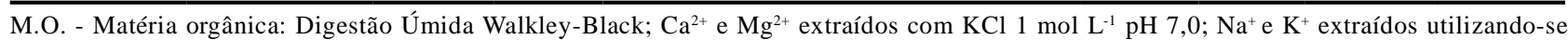
$\mathrm{NH}_{4} \mathrm{OAc} 1 \mathrm{~mol} \mathrm{~L}^{-1} \mathrm{pH} 7,0 ; \mathrm{pH}_{\mathrm{ps}}-\mathrm{pH}$ da pasta de saturação; $\mathrm{CE}_{\mathrm{es}}$ - condutividade elétrica do extrato de saturação 
de cada racemo atingiram a maturação fisiológica, tendo sido completada a secagem por exposição ao sol por três dias. Após a secagem, determinou-se o NFrutRP e o NFrutRS e posteriormente, os frutos foram debulhados manualmente e, em seguida, mensurou-se o NSRP, NSRS, MSRP e a MSRS usando balança analítica.

Determinou-se o teor de óleo das sementes no Laboratório Multidisciplinar da Embrapa Algodão, em Campina Grande, PB, após a secagem e beneficiamento, com umidade corrigida para $10 \%$, de forma não destrutiva e com uso de um espectrômetro de ressonância magnética nuclear (RMN) H1 Oxford MQA 7005 (AMERICAN OIL CHEMISTS' SOCIETY, 2000).

Avaliaram-se os dados obtidos mediante análise de variância pelo teste $\mathrm{F}$ e, nos casos de significância, realizaram-se as análises de regressão linear e polinomial, pelo software SISVAR-ESAL (FERREIRA, 2003). A escolha da regressão foi feita mediante melhor ajuste em base de coeficiente de determinação $\left(\mathrm{R}^{2}\right)$ e considerando uma provável explicação biológica para os tratamentos estudados. Diante da heterogeneidade dos dados percebidos através dos valores de coeficiente de variação (Tabela 2 e 3), foi necessário realizar análise exploratória dos dados, com transformação de dados em $\sqrt{ } \mathrm{x}$.

\section{RESULTADOS E DISCUSSÃO}

Verifica-se com base nos valores da análise de variância (Tabela 2), haver a ocorrência de efeito significativo da salinidade da água de irrigação sobre todas as variáveis estudadas. Já o fator adubação nitrogenada (N) promoveu efeito significativo sobre o NDRS e o NFrutRP. Em relação à interação entre a salinidade da água de irrigação e as doses de adubação nitrogenada houve efeito significativo apenas para CERP e CERS.

O estresse salino da água de irrigação evidenciou efeitos mais acentuados sobre o NDRP e no NDRS das plantas irrigadas com água de CEa de 3,9 dS m${ }^{-1}$ (Figura 1A), ao qual prolongaram o tempo de emissão dos racemos em aproximadamente dez e onze dias respectivamente, em comparação com as plantas que foram submetidas à CEa de $0,3 \mathrm{dS} \mathrm{m}^{-1}$. O fato do NDRP e do NDRS ter aumentado com o incremento da $\mathrm{CEa}$ pode estar relacionado à genética da planta em ajustar-se osmoticamente na fase inicial de desenvolvimento alocando maior quantidade de energia para acumulação de açúcares, ácidos orgânicos e íons no vacúolo, energia essa, que poderia ser utilizada no crescimento e produção da planta e, consequentemente, o florescimento da cultura é prolongado (SANTOS et al., 2012). Silva et al. (2008) em estudo avaliando os efeitos da $\mathrm{CEa}\left(0,7 \mathrm{a} 6,7 \mathrm{dS} \mathrm{m} \mathrm{m}^{-1}\right)$ sobre a produção da mamoneira BRS Energia, em casa de vegetação, verificaram que o NDRP teve incremento de 13 dias nas plantas sob CEa de $4,7 \mathrm{dS} \mathrm{m}^{-1}$ em relação às sob CEa de $0,7 \mathrm{dS} \mathrm{m}^{-1}$.

A aplicação de doses de adubação nitrogenada influenciou significativamente o NDRS da mamoneira onde o modelo linear crescente (Figura 1B) foi o que melhor se ajustou aos dados, ocorrendo aumento de 2,55\% por cada aumento de $30 \mathrm{mg} \mathrm{N} \mathrm{kg}^{-1} \mathrm{de}$ solo, ou seja, quando submeteram-se as plantas a doses de $160 \mathrm{mg} \mathrm{N} \mathrm{kg}^{-1}$ de solo o tempo para emissão do racemo foi prolongado em aproximadamente três dias, em comparação as que estavam sob adubação de $70 \mathrm{mg} \mathrm{N} \mathrm{kg}^{-1}$ de solo. Em relação

Tabela 2 - Resumo da análise de variância para número de dias para emissão do racemo primário (NDRP) e secundário (NDRS), comprimento efetivo do racemo primário (CERP) e secundário CERP),número de frutos no racemo primário (NFrutRP) e secundário (NFrutRS) da mamoneira sob diferentes níveis de salinidade da água de irrigação e doses de nitrogênio

\begin{tabular}{lcccccc}
\hline \multirow{2}{*}{ Fonte de Variação } & \multicolumn{6}{c}{ Teste F } \\
\cline { 2 - 6 } & NDRP & NDRS & CERP & CERS $^{1}$ & NFrutRP $^{1}$ & NFrutRS $^{1}$ \\
\hline Níveis salino (S) & $203,7^{* *}$ & $266,4^{* *}$ & $373,8^{* *}$ & $234,4^{* *}$ & $5954,4^{* *}$ & $1429,3^{* *}$ \\
Reg. Linear & $740,0^{* *}$ & $891,0^{* *}$ & $1107,1^{* *}$ & $920,9^{* *}$ & $19943,4^{* *}$ & $5433,8^{* *}$ \\
Reg. Quadrática & $66,8^{*}$ & $158,1^{*}$ & $155,2^{*}$ & $5,52^{\text {ns }}$ & $166,0^{\text {ns }}$ & $207,0^{*}$ \\
Doses de N (N) & $10,5^{\text {ns }}$ & $48,3^{*}$ & $77,96^{\text {ns }}$ & $34,2^{\text {ns }}$ & $3120,9^{*}$ & $227,6^{\text {ns }}$ \\
Reg. Linear & $9,3^{\text {ns }}$ & $82,1^{*}$ & $55,9^{\text {ns }}$ & $66,5^{\text {ns }}$ & $5852,0^{*}$ & $0,1^{\text {ns }}$ \\
Reg. Quadrática & $1,3^{\text {ns }}$ & $14,0^{\text {ns }}$ & $14,8^{\text {ns }}$ & $2,8^{\text {ns }}$ & $1016,8^{*}$ & $47,7^{\text {ns }}$ \\
Interação (S x N) & $7,1^{\text {ns }}$ & $22,2^{\text {ns }}$ & $83,5^{*}$ & $33,9^{*}$ & $513,5^{\text {ns }}$ & $70,0^{\text {ns }}$ \\
Bloco & $1,7^{\text {ns }}$ & $28,8^{\text {ns }}$ & $36,1^{\text {ns }}$ & $14,2^{\text {ns }}$ & $192,6^{\text {ns }}$ & $5,8^{\text {ns }}$ \\
CV $(\%)$ & 9,0 & 9,7 & 20,7 & 12,3 & $14,3^{2}$ & 14,1 \\
\hline
\end{tabular}

$\mathrm{ns},{ }^{* *},{ }^{*}$ respectivamente não significativo, significativo a $\mathrm{p}<0,01$ e p $<0,05 ;{ }^{1}$ análise estatística realizada após transformação de dados em $\sqrt{\mathrm{X}}$ 
Figura 1 - Número de dias para emissão do racemo (NDR) primário (NDRP) e secundário (NDRS) da mamoneira, em função da condutividade elétrica da água de irrigação - $\mathrm{CEa}(\mathrm{A})$ e das doses de adubação nitrogenada (B)

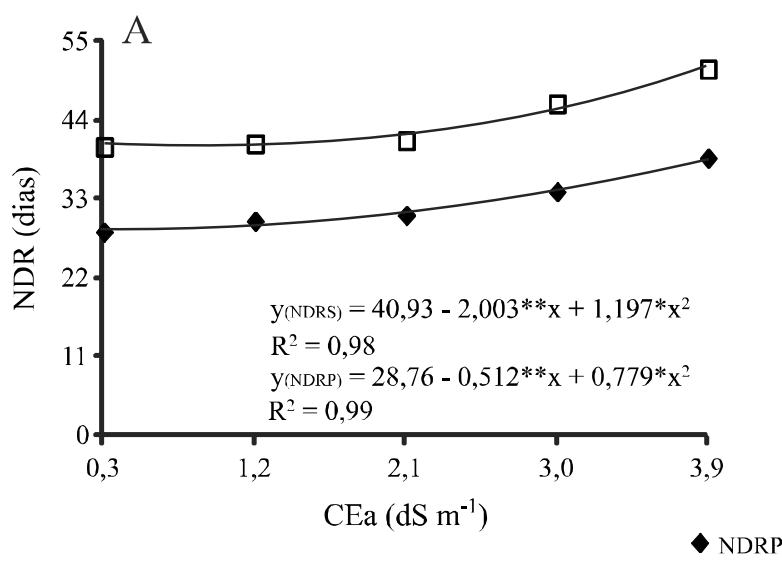

ao NDRP as plantas quando adubadas com doses de $\mathrm{N}$ variando de 70 a $160 \mathrm{mg} \mathrm{N} \mathrm{kg}^{-1}$ de solo não tiveram efeito significativo, ocorrendo a emissão do racemo primário em média aos 32 DAS. O aumento do tempo para início do estádio de florescimento pode ser atribuído às funções do nitrogênio na planta, promovendo o crescimento vegetativo e, principalmente, devido participar de diversos compostos orgânicos vitais ao vegetal, assim um aumento no teor de $\mathrm{N}$ estimula o crescimento (BARHOUMI et al., 2010) e em consequência prolonga o estádio reprodutivo da cultura.

A interação significativa entre os fatores $S$ X N para o comprimento efetivo do RP e RS estão apresentados na Figura 2A, 2B. O modelo ao qual os dados se adequaram melhor para as plantas adubadas com 100, 130 e $160 \mathrm{mg} \mathrm{N} \mathrm{kg}^{-1}$ de solo foi o linear, cujos decréscimos sobre o CERP foram respectivamente de 10,$92 ; 11,63$ e 4,34\% para cada incremento unitário da $\mathrm{CEa}$, ou seja, quando submeteram as plantas a irrigação com água de $\mathrm{CEa}$ de 3,9 dS m${ }^{-1}$, houve uma diminuição no comprimento efetivo do racemo primário de 15,43 ; 14,79 e 5,97 cm, quando comparadas às que estavam sendo irrigadas com água de $0,3 \mathrm{dS} \mathrm{m} \mathrm{m}^{-1}$. Em relação às plantas que receberam a dosagem de $70 \mathrm{mg} \mathrm{N} \mathrm{kg}^{-1}$ de solo, vê-se conforme estudos de regressão (Figura 2A) não haver efeito significativo sobre CERP, sendo alcançado um valor médio de $27,43 \mathrm{~cm}$. As plantas cultivadas sob salinidade tendem a absorver menos nitrogênio enquanto que os níveis de $\mathrm{Cl}^{-}$absorvidos e acumulados são acrescidos (BOSCO et al., 2009), em consequência do efeito antagônico existente entre íons de nitrato e de cloro, podendo proporcionar desbalanço nutricional na planta e, em consequência ocorre redução no crescimento e desenvolvimento, influenciando diretamente na produção da cultura (SILVA et al., 2008).

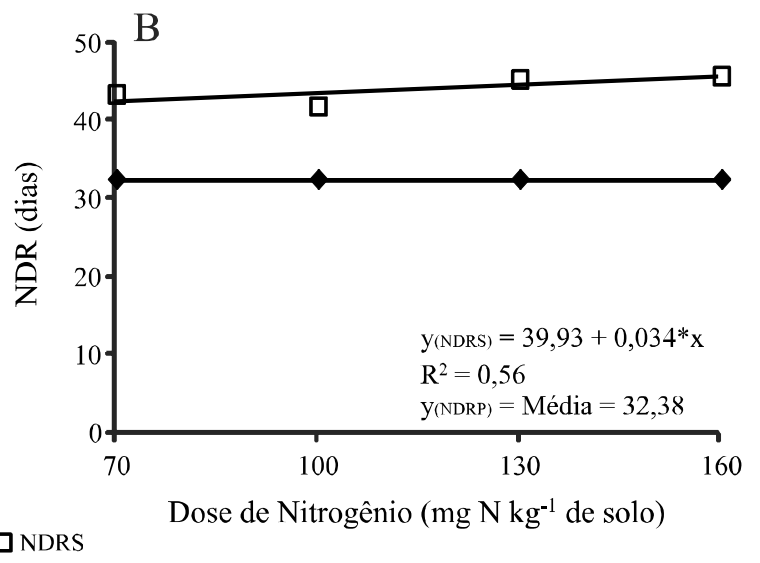

O comprimento efetivo do racemo secundário variou em função da interação entre os fatores estudados $(\mathrm{S} \times \mathrm{N})$ e conforme Figura $2 \mathrm{~B}$ verifica-se que os dados para as doses de 70; 100 e $130 \mathrm{mg} \mathrm{N} \mathrm{kg}^{-1}$ de solo apresentaram efeito linear decrescente, indicando declínio respectivamente de 13,$31 ; 14,72 ; 16,62$ e 2,93\% no CERS por aumento unitário da condutividade elétrica da água de irrigação, ou seja, as plantas ao serem irrigadas com água de CEa de 3,9 dS m ${ }^{-1}$ tiveram uma redução de 47,92; 53,$02 ; 59,85$ e 10,55\% no CERS em relação as plantas sob irrigação com nível de salinidade de $0,3 \mathrm{dS} \mathrm{m}{ }^{-1}$. Observase ainda na Figura $2 \mathrm{~B}$ que, os maiores valores para CERS $(19,91 ; 24,42 ; 24,21$ e $17,50 \mathrm{~cm})$ foram obtidos quando se irrigou as plantas com água de CEa de $0,3 \mathrm{dS} \mathrm{m}^{-1}$ sendo que, a partir desta, a tendência foi de redução do CERS agravando-se nos níveis salinos mais elevados. A redução do CERS pode está relacionada à menor absorção de água e nutrientes pela planta, decorrente do aumento dos níveis de salinidade do solo, podendo ir além de uma simples redução no potencial hídrico até a injúria celular, causada por um estresse oxidativo na planta, resultando em diminuição na produção, assim, como foi observado por GARCIA et al. (2010) na cultura do feijoeiro.

Segundo equação de regressão (Figura 3A) o maior valor para NFrutRP (118,2 frutos) foi obtido quando submeteram-se as plantas a salinidade da água de $0,3 \mathrm{dS} \mathrm{m} \mathrm{m}^{-1}$, sendo que a partir desta, houve diminuição, obtendo-se nas plantas sob maior CEa $\left(3,9 \mathrm{dS} \mathrm{\textrm {m } ^ { - 1 } )}\right.$ NFrutRP igual a 66,6 frutos, ou seja, redução de 51,5 frutos nas plantas sob CEa 3,9 dS m ${ }^{-1}$ em comparação à testemunha. Em relação ao número de frutos no racemo secundário, vê-se comportamento semelhante ao ocorrido com o NFrutRP ou seja, conforme equação de regressão (Figura 3A) as plantas quando foram submetidas à irrigação com água de 
CEa de 0,3 dS m ${ }^{-1}$ apresentaram maior NFrutRS (38,6 frutos) e as sob CEa de 3,9 $\mathrm{dS} \mathrm{m}^{-1}$ os menores NFrutRS (11,7 frutos) correspondente a uma redução de $69,79 \%$. Os estresses provocados pelo excesso de íons, em geral, diminuem a assimilação de $\mathrm{CO}_{2}$, condutância estomática, transpiração e fotossíntese das plantas e, consequentemente, acabam por prejudicar a produção e a produtividade das culturas (GULZAR; KHAN; UNGAR, 2003). Silva et al. (2008) observaram redução no NFrutRP com o incremento da $\operatorname{CEa}\left(0,7\right.$ a $\left.6,7 \mathrm{dS} \mathrm{m}^{-1}\right)$, verificando-se ainda que, a cultivar de mamoneira BRS Paraguaçu não chegou a frutificar quando irrigada com água acima de $4,7 \mathrm{dS} \mathrm{\textrm {m } ^ { - 1 }}$.

Analisando o NFrutRP em função da adubação nitrogenada verifica-se (Figura 3B) que o modelo de regressão ao qual os dados se ajustaram melhor foi o linear, indicando aumento na ordem de $15,74 \%$ por aumento de 30 mg $\mathrm{N} \mathrm{kg}^{-1}$ de solo. Comparando-se os valores obtidos nas plantas sob doses de $160 \mathrm{mg} \mathrm{N} \mathrm{kg}^{-1}$ de solo em relação às que receberam $70 \mathrm{mg} \mathrm{N} \mathrm{kg}^{-1}$ de solo, verificase incremento em cerca de 59,24\% (32,04 frutos) no NFrutRP. Com relação ao NFrutRS, observa-se (Figura 3B) que as plantas sob distintas doses de N (70 a 160 $\mathrm{mg} \mathrm{N} \mathrm{kg}{ }^{-1}$ de solo) produziram em média 27,3 frutos. $\mathrm{O}$ uso eficiente de $\mathrm{N}$ é de extrema importância econômica para os sistemas de produção e a perda deste no sistema solo-planta cria um desafio único para seu correto manejo (FAGERIA; BALIGAR, 2006), neste sentido, contata-se (Figura 3B) que o incremento das doses de $\mathrm{N}$ foi de suma importância para que se obtivesse incremento na produção.

Figura 2 - Comprimento efetivo do racemo primário-CERP (A) e secundário-CERS (B) da mamoneira, em função da condutividade elétrica da água de irrigação e das doses de adubação nitrogenada
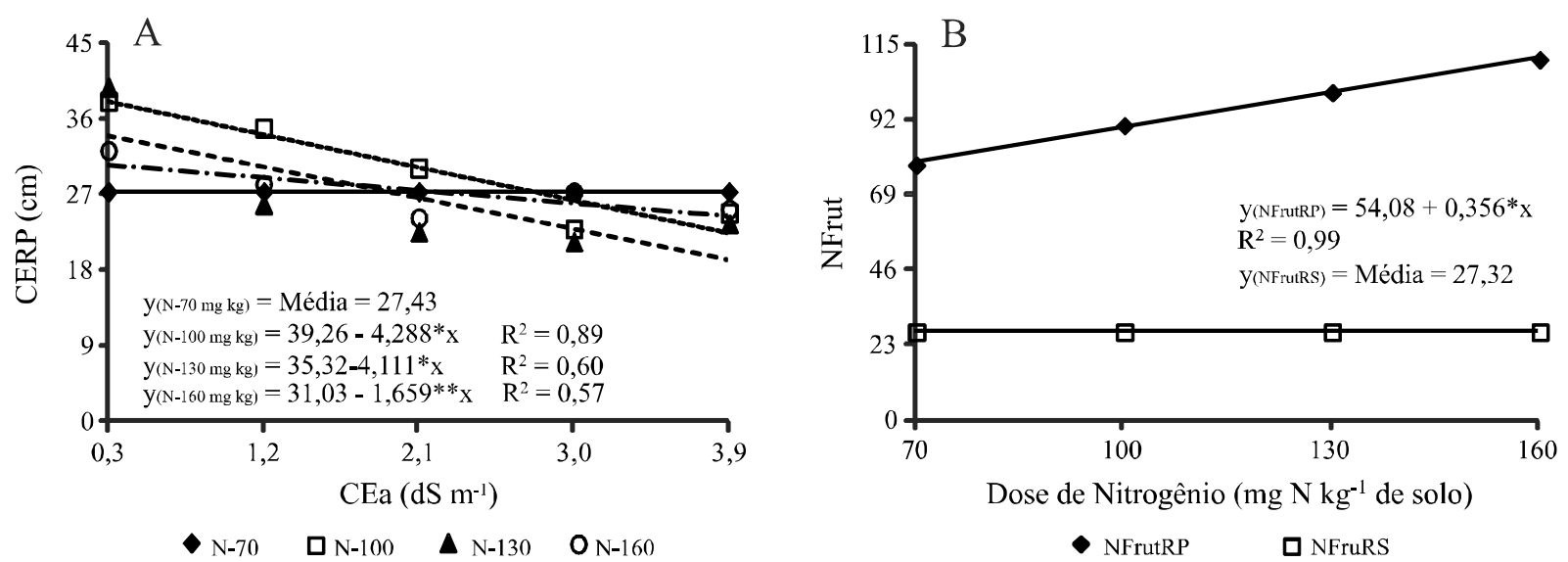

Figura 3 - Número de frutos (NFrut) no racemo primário (NFrutRP) e secundário (NFrutRS) da mamoneira, em função da condutividade elétrica da água de irrigação (A) e das doses de adubação nitrogenada (B)
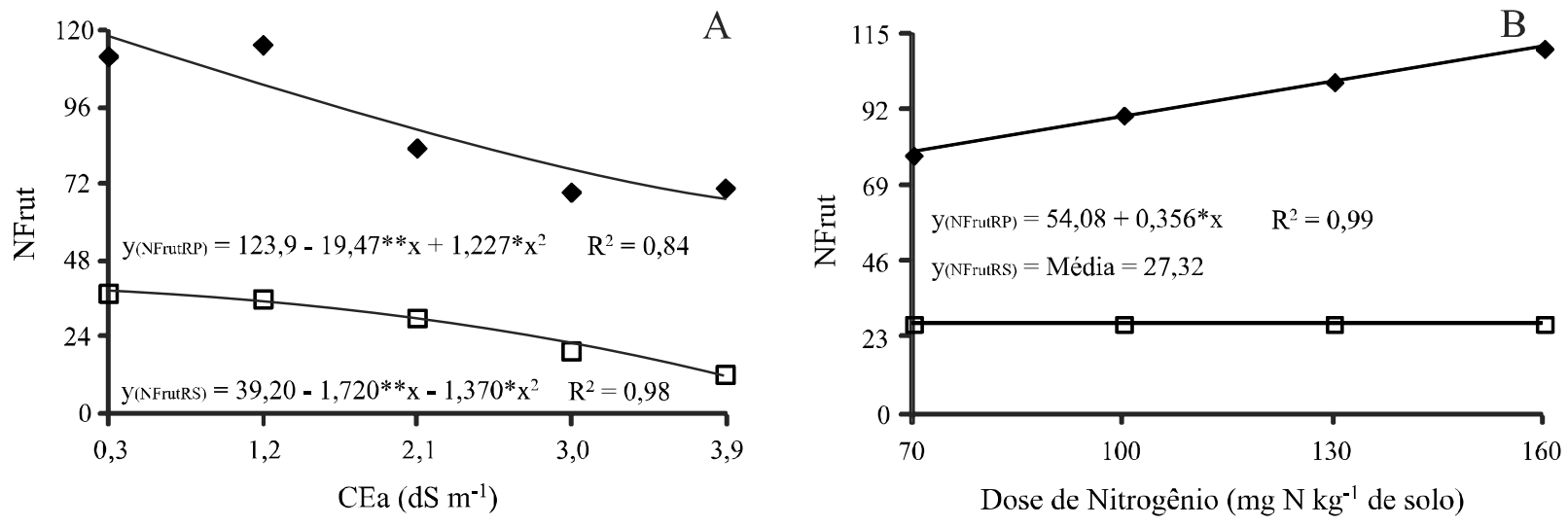

NFrutRP $\square$ NFRutRS 
Conforme resultados da análise de variância (Tabela 3) verifica-se que a salinidade da água afetou significativamente o número de sementes do racemo primário (NSRP) e secundário (NSRS), a massa de sementes do racemo primário (MSRP) e secundário (MSRS) e o teor de óleo nas sementes do racemo primário (TOrp) e da produção subsequente (TOps); constata-se, ainda, que o fator doses de adubação nitrogenada, assim como, a interação entre os fatores $(\mathrm{S} \times \mathrm{N})$ promoveu efeito significativo apenas sobre o teor de óleo nas sementes da produção subsequente.

De acordo com as equações de regressão (Figura 4A), o efeito foi linear, ocorrendo decréscimos na ordem de $10,47 \%$ no NSRP por incremento unitário da $\mathrm{CEa}$, ou seja, entre os níveis de salinidade $3,9 \mathrm{dS} \mathrm{m}^{-1}$ e $0,3 \mathrm{dS} \mathrm{m}^{-1}$ houve uma redução de 122,22 sementes $(37,69 \%)$. Em relação ao NSRS (Figura 4A), a resposta das plantas foi quadrática, onde se constata que o maior número de sementes (109,73 sementes) foi obtido quando as plantas foram submetidas à CEa de $0,3 \mathrm{dS} \mathrm{m}^{-1}$ e obtiveram o valor mínimo de 31,49 sementes nas plantas sob irrigação

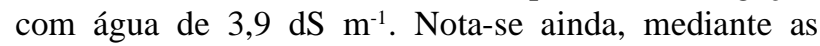
equações de regressão (Figura 4A), que o aumento da CEa afetou de forma mais severa o NSRS, indicando uma redução na ordem de 157,04 sementes em comparação ao número NSRP, quando submeteram-se as plantas à salinidade da água de $3,9 \mathrm{dS} \mathrm{m}{ }^{-1}$. A redução no número de sementes pode está relacionada aos efeitos tóxicos

Tabela 3 - Resumo da análise de variância para número de sementes do racemo primário (NSRP) e secundário (NSRS), massa de sementes do racemo primário (MSRP) e secundário (MSRS), teor de óleo nas sementes do racemo primário (TOrp) e da produção subsequente (TOps) da mamoneira sob diferentes níveis de salinidade da água de irrigação e doses de nitrogênio

\begin{tabular}{|c|c|c|c|c|c|c|}
\hline \multirow{2}{*}{ Fonte de Variação } & \multicolumn{6}{|c|}{ Teste F } \\
\hline & $\mathrm{NSRP}^{1}$ & $\mathrm{NSRS}^{1}$ & MSRP $^{1}$ & MSRS $^{1}$ & TOrp & TOps \\
\hline Níveis salino $(\mathrm{S})$ & $37510,9 * *$ & $12032,8 * *$ & $4350,7 * *$ & $1076,5 * *$ & $40,0 *$ & $55,5 * *$ \\
\hline Reg. Linear & $108408,3 * *$ & $45922,9 * *$ & $15743,9 * *$ & $4089,6^{* *}$ & $110,9 *$ & $181,1 * *$ \\
\hline Reg. Quadrática & $2066,4^{\mathrm{ns}}$ & $1224,1^{*}$ & $320,7^{\mathrm{ns}}$ & $0,15^{\mathrm{ns}}$ & $11,5^{\mathrm{ns}}$ & $39,3 * *$ \\
\hline Doses de $N(N)$ & $7220,9^{\text {ns }}$ & $1960,8^{\mathrm{ns}}$ & $499,6^{\mathrm{ns}}$ & $77,3^{\mathrm{ns}}$ & $20,2^{\mathrm{ns}}$ & $17,2 * *$ \\
\hline Reg. Linear & $1693,1^{\mathrm{ns}}$ & $102,6^{\mathrm{ns}}$ & $519,0^{\mathrm{ns}}$ & $4,0^{\mathrm{ns}}$ & $35,1^{\mathrm{ns}}$ & $17,7^{*}$ \\
\hline Reg. Quadrática & $4115,1^{\mathrm{ns}}$ & $683,4^{\mathrm{ns}}$ & $281,2^{\mathrm{ns}}$ & $34,4^{\mathrm{ns}}$ & $11,52^{\mathrm{ns}}$ & $2,5^{\mathrm{ns}}$ \\
\hline Interação (S x N) & $4389,3^{\mathrm{ns}}$ & $454,6^{\mathrm{ns}}$ & $341,1^{\mathrm{ns}}$ & $49,1^{\mathrm{ns}}$ & $2,1^{\mathrm{ns}}$ & $9,0^{*}$ \\
\hline Bloco & $1601,7^{\mathrm{ns}}$ & $250,3^{\mathrm{ns}}$ & $53,5^{\text {ns }}$ & $11,2^{\mathrm{ns}}$ & $12,7^{\mathrm{ns}}$ & $2,1^{\mathrm{ns}}$ \\
\hline $\mathrm{CV}(\%)$ & 17,5 & 15,1 & 13,8 & 18,9 & 6,9 & 27,6 \\
\hline
\end{tabular}

$\mathrm{ns},{ }^{* *},{ }^{*}$ respectivamente não significativo, significativo a p $<0,01$ e $\mathrm{p}<0,05 ;{ }^{1}$ análise estatística realizada após transformação de dados em $\sqrt{\mathrm{X}}$

Figura 4 - Número de sementes no racemo (NSR) primário (NSRP) e secundário (NSRS) por planta (A) e massa de sementes no racemo (MSR) primário (MSRP) e secundário (MSRS) (B) da mamoneira, em função da condutividade elétrica da água de irrigação

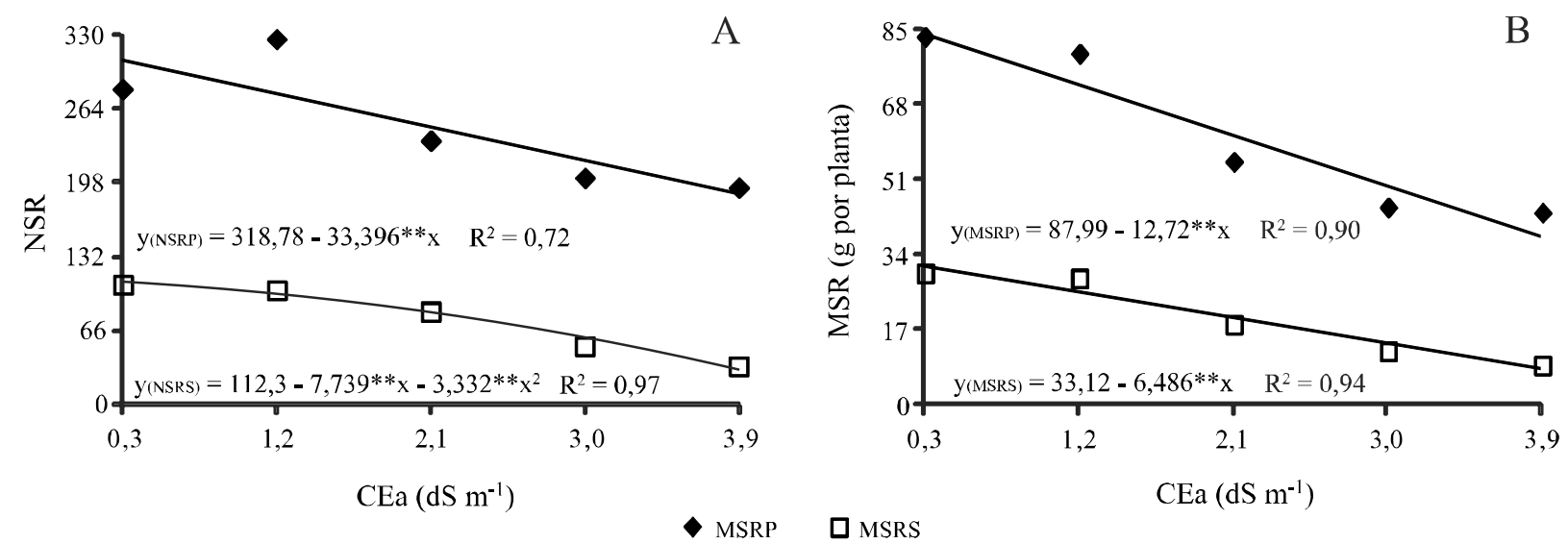


dos sais absorvidos pelas plantas, principalmente $\mathrm{Na}^{+}$ e $\mathrm{Cl}^{-}$, à baixa capacidade de ajustamento osmótico da cultura e à redução do potencial total da água provocada pelo aumento da concentração salina. Esse conjunto de adversidades possivelmente, comprometeu a atividade fisiológica, resultando em perdas da capacidade da cultura de produção (ARRUDA et al., 2002).

$\mathrm{Na}$ Figura 4B, nota-se que os dados ajustaram-se ao modelo linear, tendo-se observado, com o aumento da salinidade da água, decréscimos relativos de 14,45 e 19,58\% por incremento unitário da CEa sobre a MSRP e a MSRS, respectivamente. Constata-se que as plantas que foram submetidas à $\mathrm{CEa}$ de $3,9 \mathrm{dS} \mathrm{m} \mathrm{m}^{-1}$ em relação às irrigadas com água de $0,3 \mathrm{dS} \mathrm{m}^{-1}$, tiveram reduções equivalentes de $45,79 \mathrm{~g}$ $(52,0 \%)$ na MSRP e 23,34 g (70,5\%) na MSRS. Analisando os decréscimos da massa das sementes (Figura 4B) percebe-se que a MSRP foi mais sensível ao aumento da $\mathrm{CEa}$, tendo apresentado redução de $22,45 \mathrm{~g}$ em relação a MSRS, quando submetida à irrigação com água de maior nível de salinidade $\left(3,9 \mathrm{dS} \mathrm{m^{-1 }}\right)$. As plantas sob estresse salino podem ter acúmulo de sais nas folhas promovendo a inibição mais acentuada da fotossíntese e, por consequência, afeta as variáveis de crescimento e produção (MUNNS; JAMES; LOUCHLI, 2006). Em geral, a salinidade do solo, causada pela água de irrigação ou pela combinação dos fatores água, solo e manejo das culturas, pode resultar em redução no número de frutos, no peso dos frutos e na massa de sementes, influenciando, diretamente a produção (RHOADES; KANDIAH; MASHALI, 2000). Nobre et al. (2013), ao estudarem o efeito dos diferentes níveis de CEa $\left(0,4\right.$ à $\left.4,4 \mathrm{dS} \mathrm{m}^{-1}\right)$ associados a doses de adubação nitrogenada sobre a produção da mamoneira cv. BRS Energia, também constataram redução na massa de sementes em virtude do incremento da salinidade, tendo sido observado declínio de 39,9 g na massa de sementes do racemo primário das plantas sob CEa de $4,4 \mathrm{dS} \mathrm{m}^{-1} \mathrm{em}$ comparação às sob CEa de $0,4 \mathrm{dS} \mathrm{m}^{-1}$.

Conforme resultado para teor de óleo nas sementes do racemo primário (Figura 5A), observa-se que os dados se ajustaram melhor ao modelo quadrático sendo o maior TOrp $(50,74 \%)$ obtido com as plantas submetidas à irrigação com água de CEa de $0,5 \mathrm{dS} \mathrm{m}^{-1}$ com posterior decréscimo a partir deste, até obtenção do valor mínimo de TOrp $(46,89 \%)$ em plantas irrigadas com CEa de 3,9 dS m ${ }^{-1}$. Constata-se (Figura 5A) que ao irrigar as plantas com água de CEa variando de 0,6 a 3,3 dS m-1, obtiveram-se TOrp superior a $48 \%$. Nota-se ainda que, à medida que houve um declínio na massa de sementes no racemo primário (Figura 4B) ocorreu também uma redução no TOrp. De acordo com Severino et al. (2006) a cultivar de mamoneira BRS Energia possui teor de óleo médio de $48 \%$ nas sementes, ou seja, valor este inferior ao encontrado no presente estudo com irrigação usando

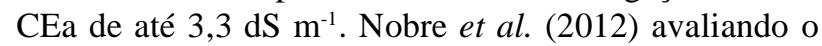
teor de óleo e a produção de sementes da mamoneira BRS Energia, submetida a irrigação com água com diferentes CEa $\left(0,4\right.$ à 4,4 $\left.\mathrm{dS} \mathrm{m}^{-1}\right)$ obtiveram um TOrp máximo de $48,18 \%$ nas plantas irrigadas com água de 0,4 dS m-1 e um mínimo de 43,38\% nas plantas sob o maior nível de salinidade da água $\left(4,4 \mathrm{dS} \mathrm{m}^{-1}\right)$.

De acordo com as equações de regressão (Figura 5B), o modelo que melhor os dados de TOps se ajustaram foi o quadrático, onde nota-se que as plantas que receberam doses de 70, 100 e $130 \mathrm{mg} \mathrm{N} \mathrm{kg}^{-1}$ de solo e que estavam sob irrigação com água de CEa de 0,$3 ; 1,5$ e $0,6 \mathrm{dS} \mathrm{m}^{-1}$ respectivamente, conseguiram promover maior TOps $(54,84 ; 55,91$ e $52,74 \%)$, já os menores valores de TOps foram obtidos quando as plantas foram irrigadas com água de CEa de 3,8;3,9

Figura 5 - Teor de óleo nas sementes do racemo primário (TOrp), em função da condutividade elétrica da água de irrigação - CEa (A) e teor de óleo nas sementes da produção subsequente (TOps) da mamoneira, em função da CEa e doses de adubação nitrogenada (B)
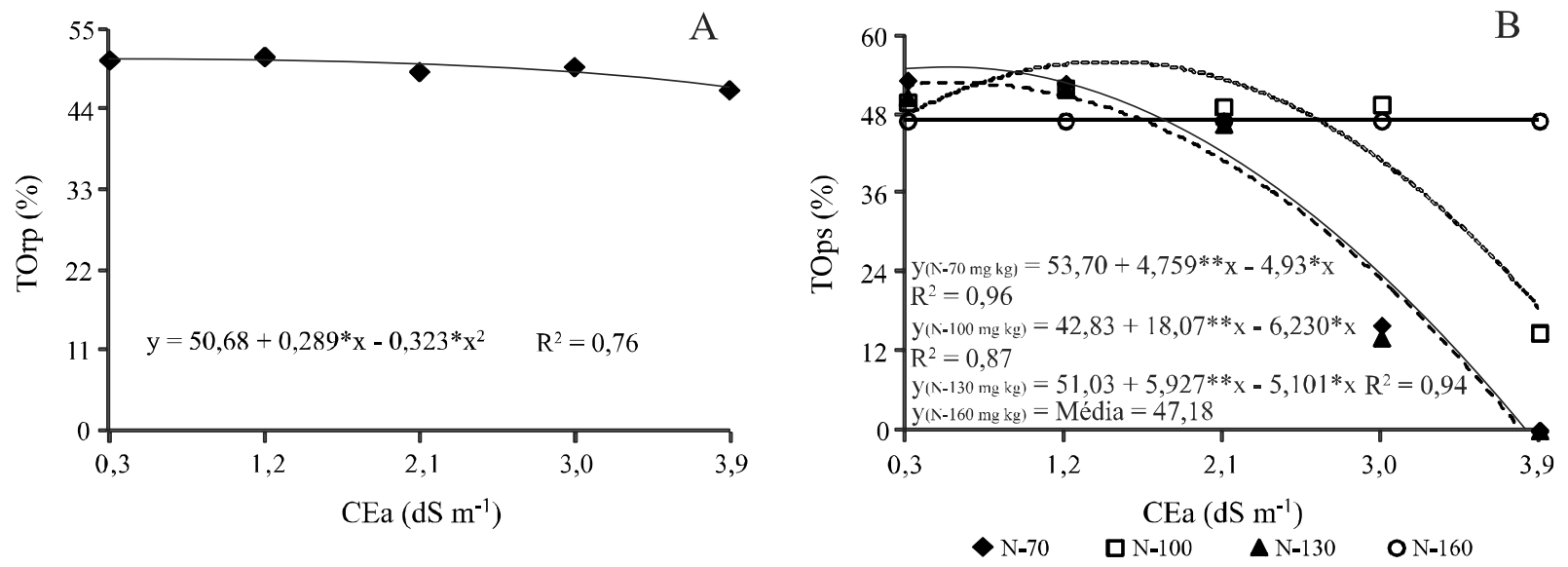
e $3,8 \mathrm{dS} \mathrm{m} \mathrm{m}^{-1}$ respectivamente; As plantas cultivadas sob dose de $160 \mathrm{mg} \mathrm{N} \mathrm{kg}^{-1}$ de solo e sob distintas CEa promoveram teor de óleo médio de $47,18 \%$ nas sementes da produção subsequente. $\mathrm{O}$ estresse salino ocasionado principalmente pela presença de íons de $\mathrm{Na}^{+}$e $\mathrm{Cl}^{-}$, pode causar disrupção na homeostase do potencial de água e desbalanço iônico na interfase solo-planta e promover toxidez no vegetal que, além de ocasionar redução na absorção de nutrientes afeta diretamente o crescimento e os componentes de produção (ASCH; DINGKUHN; DORFFING, 2000).

\section{CONCLUSÕES}

1. O incremento salino das águas de irrigação resulta em redução no número de frutos, número de sementes e na massa de sementes do racemo primário e secundário;

2. A utilização de água com condutividade elétrica de até 3,9 $\mathrm{dS} \mathrm{m} \mathrm{m}^{-1}$ prolonga o período para a emissão do racemo primário e secundário da mamoneira em dez e onze dias, respectivamente;

3. A irrigação com água de $\mathrm{CEa}$ até $3,8 \mathrm{dS} \mathrm{m}^{-1}$ proporciona teor de óleo nas sementes do racemo primário superior a $48 \%$;

4. A aplicação de doses crescentes de nitrogênio aumenta o número de frutos no racemo primário e o tempo para emissão do racemo secundário;

5. A interação entre a salinidade de água de irrigação e dose de nitrogênio afeta significativamente o comprimento efetivo do racemo primário e secundário e o teor de óleo nas sementes da produção subsequente.

\section{AGRADECIMENTOS}

Ao Conselho Nacional de Pesquisa e Desenvolvimento Científico e Tecnológico - CNPq, pelo financiamento do projeto (Edital Universal) e à Coordenação de Aperfeiçoamento de Pessoal de Nível Superior - CAPES, pela concessão de bolsa de estudo ao primeiro autor.

\section{REFERÊNCIAS}

AMERICAN OIL CHEMISTS' SOCIETY. Official methods and recommended practices of the AOCS. 5. ed. Champaign: AOCS, 2000.

ARRUDA, F. P. et al. Efeito do estresse hídrico na emissão/ abscisão de estruturas reprodutivas do algodoeiro herbáceo cv. CNPA 7H. Revista Brasileira de Engenharia Agrícola e Ambiental, v. 6, n. 1, p. 21-27, 2002.

ASCH, F.; DINGKUHN, M.; DORFFING, K. Salinity increases $\mathrm{CO}_{2}$ assimilation but reduces growth in field grown irrigated rice. Plant Soil, v. 218, n. 1/2, p. 1-10, 2000.

ASHRAF M.; HARRIS, P. J. C. Potential biochemical indicators of salinity tolerance in plants. Plant Science, v. 166, n. 1, p. 3-16, 2004

BARHOUMI, Z. et al. Nitrogen and $\mathrm{NaCl}$ salinity effects on the growth and nutrient acquisition of the grasses Aeluropus littoralis, Catapodium rigidum, and Brachypodium distachyum. Journal of Plant Nutrition and Soil Science, v. 173, n. 1, p. 149-157, 2010.

BOSCO, M. R. O. et al. Influência do estresse salino na composição mineral da berinjela. Revista CiênciaAgronômica, v. 40, n. 2, p. 157-164, 2009.

CLAESSEN, M. E. C. (Org.). Manual de métodos de análise de solo. 2. ed. rev. atual. Rio de Janeiro: Embrapa- CNPS, 1997. 212 p. (Embrapa-CNPS. Documentos, 1).

FAGERIA, N. K. Solos tropicais e aspectos fisiológicos das culturas. Brasília: EMBRAPA-DPU, 1989. 425 p. (Documentos, 18).

FAGERIA, N. K.; BALIGAR, V. C. Enchancing nitrogen use efficiency in crop plants. Advances in Agronomy, n. 88, n. 1, p. 97-185, 2006

FERREIRA, D. F. SISVAR 4,6 - programa de análise estatística. Lavras: Universidade Federal de Lavras, 2003. 1 CD-ROM.

FLORES, P. et al. Response to salinity of tomato seedlings with a split-root system: Nitrate uptake and reduction. Journal of Plant Nutrition, v. 25, n. 1, p.177-187, 2002.

GARCIA, G. de O. et al. Respostas de genótipos de feijoeiro à salinidade. Engenharia na Agricultura, v. 18, n. 4, p. 330$338,2010$.

GULZAR, S.; KHAN, M. A.; UNGAR, I.A. Salt tolerance of a coastal salt marsh grass. Soil Science and Plant Analysis, v. 34 , n. $17 / 18$, p. $2595-2605,2003$

LIMA, C. B. et al. Desenvolvimento da mamoneira, cultivada em vasos, sob diferentes níveis de salinidade da água em latossolo vermelho-amarelo eutrófico. Revista Caatinga, v. 21 , n. 5 , p. 50-56, 2008.

LIRA, M. A.; BARRETO, F. P. Oleaginosas com fonte de matéria-prima para a produção de biodiesel. Natal: EMPARN, 2009. 64 p.

MARINHO, A. B. et al. Influência da fertirrigação da nitrogenada na produtividade da cultura da mamoneira. Revista Brasileira de Agricultura Irrigada, v. 4, n. 1, p. 31-42, 2010.

MILLER, A. J.; CRAMER, M. D. Root nitrogen acquisition and assimilation. Plant and Soil, v. 274, n. 1, p. 1-36, 2004.

MUNNS, R.; JAMES, R. A.; LAUCHLI, A. Approaches to increasing the salt tolerance of wheat and other cereals. Journal of Experimental Botany, v. 57, n. 5, p. 1025-1043, 2006. 
MUNNS, R.; TESTER, M. Mechanisms of salinity tolerance. Annual Review of Plant Biology, v. 59, n. 1, p. 651-681, 2008.

NOBRE, R. G. et al. Teor de óleo e produtividade da mamoneira de acordo com a adubação nitrogenada e irrigação com água salina. Pesquisa Agropecuária Brasileira, v. 47, n. 7, p. 991-999, 2012.

NOBRE, R. G. et al. Emergência, crescimento e produção da mamoneira sob estresse salino e adubação nitrogenada. Revista Ciência Agronômica, v. 44, n. 1, p. 76-85, 2013.

NOVAIS, R. F.; NEVES J. C. L.; BARROS N. F. Ensaio em ambiente controlado. In: OLIVEIRA, A. J. Métodos de pesquisa em fertilidade do solo. Brasília: Embrapa-SEA, 1991. p. 189-253.

OLIVEIRA, F. A. et al. Desenvolvimento e concentração de nitrogênio, fósforo e potássio no tecido foliar da berinjela em função da salinidade. Revista Brasileira de Ciências Agrárias, v. 6, n. 1 , p. $37-45,2011$.
RHOADES, J. D.; KANDIAH, A.; MASHALI, A. M. Uso de águas salinas para produção agrícola. Campina Grande: UFPB,. 2000. 117 p. (Estudos da FAO, Irrigação e Drenagem, 48).

SANTOS, B. dos et al. Produção e parâmetros fisiológicos do amendoim em função do estresse salino. Revista Idesia, v. 30, n. 2, p. 69-74, 2012.

SEVERINO, L. S. et al. Produtividade e crescimento da mamoneira em resposta à adubação orgânica e mineral. Pesquisa Agropecuária Brasileira, v. 41, n. 5, p. 879- 882, 2006.

SILVA, S. M. S. et al. Desenvolvimento e produção de duas cultivares de mamoneira sob estresse salino. Revista Brasileira de Engenharia Agrícola e Ambiental, v. 12, n. 4, p. 335- 342, 2008.

SILVA, S. M. S. et al. Dotações hídricas em densidades de plantas na cultura da mamoneira cv. BRS Energia. Revista Brasileira de Ciências Agrárias, v. 4, n. 3, p. 338- 348, 2009. 